\title{
Commodity value measurement and connotative value currency
}

\begin{abstract}
Goods of utility, in the final analysis, contain two parts of natural value and labor value: the natural value is created by god and given to us for free, the labor value is the human labor which is condensed in the commodity without any difference, and the commodity value is reflected by the labor value. The essence of human labor is the process of consuming the energy and life time of the body and doing physical work to the object of labor. The value of labor, W, is the square root of the product of the energy consumed by the worker, E, and the time spent on labor, $\mathrm{T}(\mathrm{W}=\sqrt{E T})$. To design a new currency that conforms to the principles of freedom and fairness -the Talent(symbol: $\mathbb{R}$ ), whose value corresponds to its value: $1 \mathbb{R}=1 \sqrt{\mathrm{JS}}, \mathrm{J}$ is joules, $\mathrm{S}$ is seconds, perform all functions of currency.
\end{abstract}

Key words : labor value; physical work function ; Talent currency 


\section{Sequence}

On the natural value of commodities, the relationship between supply and demand of commodities and prices, etc., there are numerous economic theories and works related over the centuries, and many brilliant achievements have been made, which have built a magnificent economic building. However, as for the value theory of commodity labor, that is, how to measure the undifferentiated human labor contained in commodities, economists and scholars differ greatly, so far there is still no agreement. This great subject is the most brilliant pearl in the laurels of economics and a major problem that has plagued economists for centuries. By discovering the formula of commodity labor value, we can understand the real meaning of money, and create a legal tender that conforms to the principle of freedom and fairness, and is superior to sovereignty. This paper tries to deduce the correct answer of this problem step by step through strict logical reasoning. 


\section{Labor is the process by which physics does work.}

1. 1 The definition of labor. In order to produce useful goods, people spend their life time and use their brains and physical strength to carry out economic activities, which are called labor, such as the activities of women gathering fruits and melons in primitive society, and the activities of men chasing wild animals. Labor has three elements: first must have a clear economic purpose, such as the manufacture of a variety of utility goods, for others to provide advisory services; The second is to consume workers' life time. For example, in order to build a canoe, Robinson spent 22 days cutting down a big tree. These 22 days were both his life time and his labor time (if he did not rest and cut down the tree). The third is the consumption of labor brain and physical strength. For example, when building a canoe, Robinson first had to think about what kind of trees were suitable for him, how to cut and chisel out the hull of the canoe, and what to make the mast and sail with. Then he had to cut down the trees himself, hollowed out the inside of the tree with a chisel, and made sails. 
1. 2 The essence of labor. Labor is the work of the mind or body. Mental labor refers to the labor with the brain nervous system as the main motor organ. Manual labor is the labor that laborer regards other physiology organ besides cerebrum nerve organ as main motion organ. But in the actual process of labor, the two kinds of labor are integrated, some of the labor needs more mental work; some jobs require more physical strength, and there is no simple mental or physical work. In the process of commodity production, mental labor is mainly responsible for the formulation of production methods and methods, and the command and coordination of physical labor; manual labor is to carry out specific production activities according to the instructions of the brain, the division of labor between the two is different. It is well known that physical labor consumes energy in the body, but mental activity also consumes energy. The human brain burns 0.1 calories per minute to survive; when concentrating, they burn about 1.5 calories per minute. By comparison, people burn about 4 calories per minute while walking. Thus it can be seen that mental labor and physical labor are essentially the process of energy consumption of the body. 
The split of human labor process, but is the natural material collection, transportation, disassembly, combination and other physical work process. Although chemical reactions or even nuclear reactions are required in some parts of the production process to produce some goods, it is impossible for us to have chemical or nuclear reactions between our bodies and the objects of labor. We can only make these reactions happen by doing physical work on the objects of labor. For example, when we rub flint against wood, it causes the wood to react chemically -- to burn, but we only apply friction to the wood, which is physical work and makes it ready to burn. Our bodies are not directly involved in the burning (otherwise we would not exist). Because labor is a physical process, so complex labor is the combination and superposition of simple labor, the two are only quantitative difference, there is no qualitative difference.

There is no doubt that whether the body expends energy, or does work on the object of labor, it needs to consume the worker's life time. The production of some goods, need to spend more energy, such as transporting stone, chasing wild animals, labor intensity is high, labor time is 
short; there are also some goods production is a fine work, such as sculpture, painting, labor intensity is not high, but to spend more time. Thus, the labor of producing different goods may consume different energy of the body and occupy different life time of the worker.

Thus it can be seen that the essence of labor is a physical process in which human beings consume energy and life time of the body and do work to the object of labor.

\section{The value of commodities is embodied by the value of}

\section{labor.}

Nature is the mother of commodities, labor is the father of commodities. Goods of utility, in the final analysis, contain two parts of natural value and labor value:the value of nature is created by god and given to us free of charge, while the value of labor is the undifferentiated human labor condensed into commodities. No labor value, equivalent to no human labor on it, the "commodity" can only exist in nature, and therefore can not become a commodity; no natural value, equivalent to the "commodity" has not been created by god, there is no object of labor, the value of labor will not exist. For us, the value of nature is free, the value of goods can only be reflected 
by the value of labor.

2. 1 The natural value of commodities. Commodity is the result of cooperative labor between nature and human, including two parts of natural labor and human labor. However, the commodities produced by the cooperation between god and human beings are not repaid to the nature, but are all possessed and dominated by human beings, which is equivalent to the fruits of natural labor are given to us for nothing. For example, during the most beautiful maple season in Canada, I caught a $10 \mathrm{~kg}$ triplet $\mathrm{fish}$ in the Adams section of the Fraser river. It took about four years for the triploid fish to grow from egg to egg, during which time nature nursed and fed it. Before I caught it, this triplet fish was none of my business, it was the work of nature. And when I caught it, the triplet fish became the work of nature and me.But I ended up owning and enjoying the triplet without paying any extra labor to nature. Thus it can be seen that the natural value contained in commodities is created by god and given freely to human beings. For us humans, the natural value of goods is zero. Therefore, the value of goods can only be reflected by the value of labor.

2. 2 Labor value included in commodities. The value of labor 
contained in a commodity (represented by the character W) is the undifferentiated human labor condensed into the commodity, that is, the sum of the mental and physical energy expended by the laborer to produce the commodity. The value of labor is not formed in one action, but is accumulated in the process of commodity production. The formation process of labor value is manifested by the consumption of energy and life time of laborers. The more energy and life time a laborer consumes to produce a commodity, the greater the labor value of the commodity; conversely, the smaller. Suppose an Eskimo spent a day capturing one seal and burned 1, 000 calories. It took three days and 2,000 calories to capture one polar bear, so a polar bear must be worth more than a seal.

\section{The production of goods requires the payment of labor.}

The laborer must pay the labor price for producing goods. The external manifestation of labor cost is the energy and life time consumed by the body.

3. 1 Direct labor cost of commodities. The laborer takes the natural things as the starting point and carrier to produce the effective commodities. He must exert the physical effects such as cutting, handling, splitting and 
combination on the natural things, so as to make them go through the corresponding physical change, chemical change or nuclear change process, and finally become the commodities we need. These physical actions of human beings are bound to consume the energy and life time of the human body, that is, to pay the direct cost of labor. The energy consumed by a worker's body is the amount of energy consumed by the body due to the production of a commodity (represented by the character E); the amount of life time consumed by a worker is the amount of life time taken up by the production of a commodity (represented by the character T).

We know that even in a sedentary, inactive day, the body burns about 1, 400 calories to stay alive. If I worked 1 day to produce a product and burned 3, 000 calories, then I would have burned $1,600(3,000-1,400)$ calories to produce that product; if my 1 day's labor is an uninterrupted continuous process, then the commodity takes up 1 day of my life, which is also the labor time. So, for me, the direct labor cost of producing this product is 1600 calories and 1 day of life.

3. 2 Necessary labor cost of commodities. Due to people's 
insufficient cognition of the mode of commodity production and the limitation of the scientific and technological level at that time, the direct labor cost paid by people to produce a commodity is usually greater than the necessary labor cost. For example, if you sawed an adult cedar tree at the right Angle and with the right amount of force, the necessary energy applied by the saw blade is 1000 calories and it takes 1 hour, then the necessary labor costs 1000 calories and 1 hour. But if a novice does it, he doesn't know the Angle of exertion, and it takes him 1, 500 calories and two hours, then his direct labor costs him 1,500 calories and two hours. As the work proficiency increases, his direct labor cost will gradually approach the necessary labor cost. Theoretically, in a certain mode of production, the production of a commodity must have the corresponding necessary labor cost, is the minimum labor cost; and the direct labor cost is usually greater than that. When the mode of commodity production changes, the necessary labor cost of commodity production must change accordingly.

3. 3 Direct labor cost is the basis of labor value measurement. In the production of a commodity under a certain mode of production, although relative to the cost 
of necessary labor, people consume part of the direct labor cost of energy and labor time is redundant and useless, but this part of energy and time is actually paid by workers, and is also necessary under the social production conditions. On the other hand, the necessary labor cost of producing goods requires a high degree of precision in the production process, which is usually impossible to achieve in real production and only has theoretical significance. Therefore, only the direct labor cost that the laborer actually produces is taken as the basis, can measure the magnitude of commodity value truly and completely. For example, the new handsaw cut cedar cost 1, 500 calories and 2 hours, although it was higher than the necessary labor cost, his direct labor cost was actually incurred, and his labor value was higher than 1,000 calories and 1 hour's labor value.

\section{Labor value is a function of direct labor cost.}

The labor value of a commodity is not the same as the direct labor cost paid by the laborer, on the other hand the two are interrelated.

4. 1 There is a causal relationship between labor value and direct labor cost. Labor value, that is, the sum of 
labor's mental and physical energy consumed in the process of commodity production, and the direct labor cost, that is, the total amount of external energy and life time consumed for the body. There is a causal relationship between the two. When people began to produce goods, workers began to use their brains and physical strength, and the body began to use energy and life time; as the next phase of continuous labor begins, the body begins to expend energy and time, and so on. Therefore, the value of labor is the cause, and the direct cost of labor is the corresponding result.

\section{2 There is a positive correlation between labor value} and direct labor cost. Suppose the worker produces two goods $\mathrm{A}$ and $\mathrm{B}$, and it takes the worker 1,000 calories and one hour of labor to produce A; it takes 2, 000 calories and two hours to produce B. There is no doubt that the labor value of good B to the worker is greater than that of good A, and 1 good $\mathrm{B}$ is equal to 2 good $\mathrm{A}$. Because the direct labor cost of the worker producing B can produce 2 good A.

If the direct labor cost of producing good $\mathrm{A}$ is the same, and producing good B also consumes 1000 calories, but it takes 2 hours of labor, then the labor value of good B is 
greater than that of good A.

If the direct labor cost of producing good $\mathrm{A}$ is the same, and it takes 1 hour of labor time to produce good B, but it takes 2000 calories, then the labor value of good B is greater than that of good A.

From the above, it can be seen that in the direct labor cost, the energy consumed by the laborer's body and the labor time consumed by the laborer are positively correlated with the labor value.

4. 3 Labor value is the binary function relationship between energy consumed and labor time. If the energy $\mathrm{E}$ and labor time $\mathrm{T}$ consumed by the labor body are regarded as independent variables, then each set of independent variables (E, T) must correspond to a fixed value, that is, labor value $\mathrm{W}, \mathrm{W}=\mathrm{f}(\mathrm{E}, \mathrm{T})$, and $\mathrm{E}$ and $\mathrm{T}$ are real numbers $\geqslant 0$, and $W$ is real numbers $\geqslant 0$, it's a function of two variables.

\section{Labor value function formula derivation.}

Given that $\mathrm{W}=\mathrm{f}(\mathrm{E}, \mathrm{T}), \mathrm{E}$ and $\mathrm{T}$ are real numbers $\geqslant 0$, respectively representing energy and time; the value of labor is also a real number greater than or equal to 0. According to the relation between the exchange of goods and the direct labor cost, the labor value function formula 
is derived.

5. 1 The two independent variables of direct labor cost are not arithmetic addition and subtraction. Given the two independent variables of direct labor cost are energy E and labor time $\mathrm{T}$, respectively, and are real numbers $\geqslant 0$. Since $\mathrm{E}$ and $\mathrm{T}$ are not the same dimensional units, $\mathrm{E} \pm \mathrm{T}$ has no practical significance. Therefore, in the function relation of $\mathrm{W}=\mathrm{f}(\mathrm{E}, \mathrm{T})$, the two arguments $\mathrm{E}$ and $\mathrm{T}$ of independent variables cannot be the relationship of arithmetic addition and subtraction.

5. 2 The two independent variables of direct labor cost are multiplied. As can be seen from 5.1, in the functional relation $\mathrm{W}=\mathrm{f}(\mathrm{E}, \mathrm{T}), \mathrm{E}$ and $\mathrm{T}$ are not arithmetic addition and subtraction, so $\mathrm{E}$ and $\mathrm{T}$ can only be multiplied or divided. According to 4.2 , W is positively correlated with $\mathrm{E}$ and $\mathrm{T}$, so $\mathrm{E}$ and $\mathrm{T}$ can only be multiplied.

5. 3 Labor value binary function derivation. Suppose E and $\mathrm{T}$ have exponents $\mathrm{n}$ and $\mathrm{m}$ respectively, and $\mathrm{n}$ and $\mathrm{m}$ are real numbers, the binary function formula of labor value is: $\mathrm{W}=\mathrm{E}^{\mathrm{n}} \mathrm{T}^{\mathrm{m}}$. The following steps are deduced to determine the values of $\mathrm{n}$ and $\mathrm{m}$ :

(1)According to 4.2 , if $\mathrm{E}_{2}=2 \mathrm{E}_{1}, \quad \mathrm{~T}_{2}=2 \mathrm{~T}_{1}$, then 
$\mathrm{W}_{2}=2 \mathrm{~W}_{1}$. Similarly, if $\mathrm{E}_{2}=\mathrm{aE}_{1}$ and $\mathrm{T}_{2}=\mathrm{aT}_{1}$, then $\mathrm{W}_{2}=\mathrm{aW}_{1}$, a is a natural number greater than 0 . So if I plug this into the formula, $\left(E_{2} / E_{1}\right)^{n} \times\left(T_{2} / T_{1}\right)^{m}=\left(W_{2} / W_{1}\right) \rightarrow$

$$
\begin{aligned}
& \left(\mathrm{aE}_{1} / \mathrm{E}_{1}\right)^{\mathrm{n}} \times\left(\mathrm{aT}_{1} / \mathrm{T}_{1}\right)^{\mathrm{m}}=\left(\mathrm{aW}_{1} / \mathrm{W}_{1}\right) \rightarrow \\
& a^{n} \times a^{m}=a \rightarrow \\
& n+m=1
\end{aligned}
$$

(2) If $n \neq m$, assuming that $n=2$, because $n+m=1$, so $m=-1$ 。

From the formula $\mathrm{W}=\mathrm{E}^{2} \mathrm{~T}^{-1} \rightarrow \mathrm{W}=\mathrm{E}^{2} / \mathrm{T}$.

However, according to $4.2, \mathrm{~W}$ is positively correlated with $\mathrm{E}$ and $\mathrm{T}$, so the $\mathrm{n} \neq \mathrm{m}$ condition is not valid.

(3) If $n=m$, because $n+m=1$, so $n=m=1 / 2$

(4) Therefore, the binary function formula of labor value is: $W=\sqrt{E T}$, the value of labor is the square root of the product of the energy expended by the laborer and the labor time. W is positively correlated with E and T.

(5)If the production of goods consists of $n$ continuous labor processes ( $\mathrm{n}$ is a natural number greater than 0 ), since $\mathrm{W}=\sqrt{E T}$ is a continuous binary function, the formula only makes sense if it conforms to the continuity. Therefore, to calculate the value of commodities in $\mathrm{n}$ continuous labor processes, the labor value of commodities added in each 
continuous labor process can only be calculated separately: $\mathbf{W}_{1}=\sqrt{E_{1} T} 1 、 \mathbf{W}_{2}=\sqrt{E_{2} T} 2 \ldots \mathbf{W}_{\mathbf{n}}=\sqrt{E_{\mathrm{n}} T_{\mathrm{n}}}$, the total labor value of producing the good: $\sum_{1}^{\mathrm{n}} \mathrm{W}=\mathrm{W}_{1}+\mathrm{W}_{2}+\ldots+\mathrm{W}_{\mathrm{n}}$.

6. Measurement of commodity labor value including capital.

The essence of capital (represented by the character K) is the solidified human labor, such as production tools, production technology, intellectual property, etc., which helps people improve the efficiency of the production of goods. In the process of commodity production, some capital is converted into goods at one time, some capital is completed after many times, and some capital such as technology, intellectual property and so on can be transformed indefinitely. The measurement method of commodity value containing capital is as follows:

6. 1 For goods that have all converted capital at one time. Let's say the capital goods value is $\mathrm{K}$, and we convert all the capital at once, production of 1 unit of the commodity value of living labor $\sum_{1}^{\mathrm{n}} \mathrm{W}$, so the value of the commodity that contains capital is: $\mathrm{K}+\sum_{1}^{\mathrm{n}} \mathrm{W}$.

6. 2 For goods whose capital has been converted for $n$ times. Suppose the value of capital goods is $\mathrm{K}$, only by 
producing $\mathrm{n}$ units of the goods can the capital be converted completely ( $\mathrm{n}$ is a natural number greater than 1), production of 1 unit of the commodity value of living labor $\sum_{1}^{\mathrm{n}} \mathrm{W}$, so the value of the commodity that contains capital is: $\mathrm{K} / \mathrm{n}+\sum_{1}^{\mathrm{n}} \mathrm{W}$.

6. 3 For goods that can convert capital indefinitely. Let's say the capital goods value is $K$, which can be converted into goods an infinite number of times, production of 1 unit of the commodity value of living labor $\sum_{1}^{\mathrm{n}} \mathrm{W}$, if the total quantity of goods produced using that capital is $m$ ( $m$ is a natural number greater than 1 ), so the value of the commodity that contains capital is: : $\mathrm{K} / \mathrm{m}+\sum_{1}^{\mathrm{n}} \mathrm{W}$.

\section{The price of commodities fluctuates around the value of labor}

In real transactions, due to the differences in the situation of commodity supply and demand, the actual transaction price of commodities (represented by the character P) will often deviate from the value of labor and fluctuate around the value of labor, but from a long-term perspective, $\mathrm{P} \approx \mathrm{W}$. When $\mathrm{P}<\mathrm{W}$, it indicates that the supply exceeds the demand. When $\mathrm{P}>\mathrm{W}$, it means that the supply 
of goods is in short supply.

\section{Design a new currency based on value}

Different commodities can be exchanged because commodities contain the undifferentiated human labor -labor value, that is commodity value. Money is a medium for the exchange of goods, but the current currency evolved from the general equivalent of gold, silver and other labor products, and it has no constant value of its own, so it cannot fairly measure the value of other goods. This paper 1-6 solves the problem of how to measure the value of commodities. Therefore, legal tender can be redesigned for its value, and a super-sovereign world currency conforming to the principles of freedom and fairness can be created.

8. 1 Money that is endowed with intrinsic value by law. Name the new currency Talent currency, symbol: $\mathbb{R}$. Correspond the value of the currency to the value of $\mathrm{W}$, and define the new currency unit: $\mathbf{W}=\sqrt{E T}$; provisions 1 Talent=1 $\sqrt{\text { joule*seconds }}$. Expressed in monetary notation:1 $\mathbb{R}=1 \sqrt{\mathrm{JS}}$ $\mathrm{J}$ is joules, $\mathrm{S}$ is seconds.

8. 2 Assume the function of monetary value measure. Since the new currency itself is given a value and the value is constant, the new currency itself is the standard measure 
of value and does not need to be linked to commodities such as gold and oil. The new currency can assume the function of value measure, which is used to measure the labor value of other goods.

\section{3 Design corresponding rules and assume all functions} of currency. No country is short of labor value, so the new currency with value as its connotation can be recognized by sovereign countries and economies, and is most likely to evolve into a super-sovereign world currency. A series of rules for the creation, circulation and demise of new money can be reasonably designed. The new money can also perform all functions such as the medium of exchange of goods, the means of circulation, the means of storage and the world's money.

9. The exchange of goods mediated by the new currency.

Special agencies set up by the government are responsible for measuring the value of commodities to be traded, and the measurement results are published publicly. The Talent currency was established as the sovereign currency of the state and assumed all functions of the currency.

9. 1 Measurement and publication of commodity value. If worker A goes through $\mathrm{n}$ continuous labor processes and 
produces 1 good A, according to 5. 3, the value of commodity A is : $\sum_{1}^{\mathrm{n}} \mathrm{W}=\mathrm{W}_{1}+\mathrm{W}_{2}+\ldots+\mathrm{W}_{\mathrm{n}}$ (the consumption of $\mathrm{E}$ and $\mathrm{T}$ by worker A in each continuous labor process shall be determined by A professional institution established by the government, and the measured value shall be close to the theoretical value), published by the platform, such as the value of commodity A $1000 \mathbb{R}$

9. 2 Conduct market transactions. When commodity A enters the market trading platform, the value of commodity A must be announced to be $1000 \mathbb{R}$; And then you can put your own price on product A, say $2000 \mathbb{R} ; B, C$ and D are willing to bid $1200 \mathbb{R}, 1300 \mathbb{R}$ and $1500 \mathbb{R}$ for A, respectively. After further negotiation, commodity A was finally bought by D for $1350 \mathbb{R}$.

9. 3 Translates into world currency. As more and more countries take Talent currency as the national sovereign currency, the division of labor system of world production and trade will be gradually rationalized, and commodity prices will gradually return to value.

Chengjinjun Anhui provincial bureau of energy cdcdcd999@126.com; 
Chengdian pudong Development bank Hefei branch $\underline{1226195145 @ q q . c o m}$

\section{Main References}

1. Ricardo's works and correspondence, volume I, Ricardo

2. General theory of employment interest and money, Keynes

3. A study of the nature and causes of national wealth, Adam Smith

4. Natural value. F. Von Wiesel 